Tohoku J. Exp. Med., 2008, 216, 287-296

\title{
Review
}

\section{The Logistics Management and Coordination in Procurement Phase of Organ Transplantation}

\author{
RuHET GENÇ ${ }^{1}$ \\ ${ }^{1}$ International Logistics and Transportation Department, Beykent University, Istanbul, Turkey
}

\begin{abstract}
The number of organ transplantation surgeries has increased particularly in the last decade due to technological and scientific advances in medicine. Despite this increase, many patients, however, remain in waiting lists for transplantation surgery. Main reasons for these waiting lists are that there are limited number of organ donations and specifically problems in the management of organ transplantation activities. An efficient management of the allocation and transportation of organs (in other words, logistics management of organ transplantation) are thus extremely important. The aim of the paper is to review current practices of logistics management in the procurement phase of organ transplantation. It initially reviews the organizational structures of the international and national coordination centres, which are founded to coordinate organ transplantation activities and to enhance collaboration among physicians and medical staff. The paper, then, focuses on the possible managerial problems encountered during the procurement phase of organ transplantation. With this respect, common transportation difficulties from global and local perspective are also analyzed. This paper tries to take attention to a systematic regard of the organ transplantation from logistics point of view, thus providing applicable solutions to managerial problems in terms of allocation and transportation of organs.

Logistics Management; Organ Transplantation; Coordination System; Transportation; Allocation Strategies.
\end{abstract}

Tohoku J. Exp. Med., 2008, 216 (4), 287-296.

(C) 2008 Tohoku University Medical Press

Due to enhanced surgical procedures, the better use of time, immunosuppressive/antimicrobial/ antiviral medications, and better organ transplantation techniques, transplantation surgeries become more feasible and reachable to more patients all over the world recently (Reynolds and Barney 1988). There has been a global increase in the number of organ transplantation surgeries for the last ten years, mainly due to technological and scientific advances in medicine and recent encouraging law regulations for transplantation surgeries (Turkish Republic Health Ministry 2002). Despite these new advances in medical world and the enhanced feasibility of transplantation surgeries, many patients still remain in waiting lists due to shortage of organs and managerial problems. In 2001 , only the $10.8 \%$ of patients were available to transplantation surgery and the $26.1 \%$ of them had, respectively, kidney transplantation and liver transplantation surgeries in Turkey and other patients remained in the organ waiting lists (Table 1) (Turkish Republic Health

Received September 3, 2008; revision accepted for publication November 12, 2008.

Correspondence: Ruhet Genç, International Logistics and Transportation Department, Beykent University, Ayazaga, Sisli, Istanbul, Turkey.

e-mail: rgenc@beykent.edu.tr 
Table 1. The Frequency of Patients that are in the Turkish National Organ Waiting List Between 2001 and 2004.

\begin{tabular}{ccccc}
\hline & Kidney & Liver & Heart & Total \\
\hline 2001 & 4526 & 414 & 199 & 5139 \\
2002 & 6060 & 430 & 146 & 6639 \\
2003 & 6501 & 351 & 191 & 7043 \\
2004 & 8536 & 759 & 183 & 9478 \\
\hline
\end{tabular}
(2005)

Source: Turkish Republic Health Ministry

TABLE 2. The Frequency of Donation in Several Countries (in 2005).

\begin{tabular}{|c|c|}
\hline & $\begin{array}{l}\text { Organ donation in numbers } \\
\text { (per one million people) }\end{array}$ \\
\hline Spain & 34.6 \\
\hline Italy & 21.1 \\
\hline France & 20.9 \\
\hline USA & 20.0 \\
\hline Germany & 13.8 \\
\hline UK & 12.3 \\
\hline Greece & 6.2 \\
\hline Turkey & 0.4 \\
\hline
\end{tabular}
(2005)

Source: Turkish Republic Health Ministry

Ministry 2005; Edirne 2004; Turkish Republic Health Ministry 2002). At the same year, almost 6,000 patients lost their lives while waiting in the organ donation list (Wiesner 2003).

These waiting lists occur due to some problems and the three main factors create the lag between demand and supply of organs (Van Gelder et al. 2008): first reason for this lag is the existence of problem in governmental organ donation policies and funding for transplantation activities. Second one is negative public attitude and the lack of knowledge and consciousness among the public to organ donation, which leads to reluctant motives towards the manner (Table 2). Third is the lack of coordination among related institutions or health care managers/physicians/nurses who are involved in organ transplant process phases.
The disorganization of institutions and specifically coordination team's failure in the organizing the suitable donors to the most suitable organ recipients are seen as the most critical reason of the shortage of organs (Miranda et al. 1999). Therefore, an efficient management of the allocation and transportation of organs to patients who are available to organ transplantation surgery are extremely important. Otherwise, any problem in these managerial issues would result in the misuse or waste of the donated organs (Williams et al. 1984).

The logistics management of the organ transplantation activities is specifically important to enhance the quality of care and increase the efficiency of the organ transplantation activities (Shaewkey and Hart 2003). There is an intersecting area between the logistics management and the organ transplantation which if managed in a planned and effective way may result in efficiency. Nevertheless, the logistics management of organ transplantation had not been discussed from a logistics point of view. This paper aims to review current practices of logistics management in the procurement phase of organ transplantation. It initially reviews the organizational structures of the international and national coordination centres for organ transplantation activities. It, then, focuses on the possible problems that physicians and organ transplant coordinators encountered during the procurement phase of organ transplantation. In order to provide meaningful suggestions to managerial problems, common transportation difficulties from global and local perspective are also reviewed.

\section{The Coordination in Organ Transplantation Activities: International and National Coor- dination Systems}

Organ transplantation process is composed of two main phases which are procurement and surgery (Fuzzati 2005). The procurement of the organ involves finding, allocation and transportation of organs to the most appropriate recipients. Surgery phase is more related to the medical part, whereas the procurement phase is highly related to logistic management. Procurement phase is 
about matching the donor organ and the right recipient. It involves planning transportation routes of the organ to the identified recipient. It, thus, requires the management of the medical teams for procurement and transplantation surgery.

For organ transplantation, time is the main and very important constraint since when organ donation process starts, within very short period of time organ procurement and transplantation surgery should be conducted (Fuzzati 2005). For instance, when heart is procured it should be transplanted to patients within four hours. Within this period, coordinators should identify the most suitable potential recipient among all possible patients, transport the organ to the target hospital and transplant the organ.

Before 80 s, the transplant activities were not officially coordinated and thus, especially the role of coordinators in the allocation of organs was not clear (Coombes and Trotter 2005). Several problems have emerged within this process. For instance, a study conducted with 575 renal procurement cases revelaed that some transplantation surgeries could not be done due to failure in the coordination of procurement team and surgery team (Williams et al. 1984). The medical staff and qualified physicians may be unavailable for that moment when an urgent procurement and transplantation surgery is needed. In most cases, even the procurement team or physicians are required for the transportation of organs. The lack of time management applications of transplant organizations is another major problem in organ transplantation coordination (Van Hees and Van Gelder 2008). Several international and national organizations are founded to handle these organizational and coordination difficulties in organ transplantation activities, such as United Network for Organ Sharing (UNOS, USA), the Organizacion Nacional de Transplantes (ONT, Spain) and Turkish National Coordination Centre (Turkey). The United Network for Organ Sharing (UNOS) is an international organization that manages the effective allocation and transportation of donor organs overseas (Coombes and Trotter 2005). There are 140 transplant centres in the
USA, which are bind to 62 local Organ Procurement Organizations. These local organizations are in charge of the procurement, preservation, and transportation of organs. When a patient refers to one of these centres within the USA or from abroad, his/her name is listed on the waiting list of UNOS. When a donor organ is available for transplantation, the organ is matched with the most suitable potential recipient, who is selected by physicians based on predetermined allocation parameters.

National coordination centres, in general, are composed of the network of national, regional and hospital coordinators. An example of such an institution is Organizacion Nacional de Transplantes (ONT) in Spain (Matesanz et al. 1994a) which is in charge of requesting and redirecting the medical status of patients in pre-evaluation phase. It supports the promotion of organ donation in the public. It is under the control of the Spanish Health Department and coordinates nearly 140 health care units. The Spanish organ transplantation coordination system has been recognized as one of the most efficient national systems (Polak et al. 2000): A central office is responsible for the allocation and transportation of organs/ transplantation teams. It manages from the registration of patients to the sharing of the donated organs between different transplant centres by coordinating air and land transportation of procured organs and medical staff. All hospitals, organize qualified procurement/coordinator teams within their systems. Transplant coordinators are usually physicians or nurses bound to the ONT, who are also required to give report to hospital directors (Matesanz et al. 1994a). They function as managers of educational programmes and resources, are responsible for administrative tasks and are also in charge of media relations.

These organizations seem to enhance much of the probable logistic management problems in organ transplantation. A study indicated that between 1992 and 1994, the completed organ procurement rate was $81 \%$ and the organ transplant rates increased by nearly $100 \%$ (Matesanz et al. 1994a; Matesanz et al. 1994b). Thus, the Spanish model is a very important one which may be 
applied as educating coordination model throughout the world. Within his regard, it was argued that international organizations such as UNOS and national organizations such as ONT have been facilitating the organ transplant activities.

\section{Turkish National Coordination System}

In 2001, a national organization was founded in Turkey - the Turkish National Coordination Centre (TNCC) - which is controlled by the Health Ministry as in the case of Spain. TNCC consisting of the National Organ and Tissue Transplantation Coordination Committee, Scientific Committees, and Coordinator Committee. It functions as organizing coordination among the regional coordination centres, involves in the preparation of nation-wide organ waiting lists, and the preparation and maintenance of urgent waiting lists. It manages the communication, cooperation and transportation of scientific consultation teams, procurement teams and local hospitals located in district cities of Turkey. It evaluates the applications of hospitals for launching organ transplantation centres in collaboration with Health Ministry. It also conducts national strategies on organ transplantation, managing the Organ Transplantation Regional Coordination Centres in nine regions of Turkey (Edirne 2004).

Organ and Tissue Transplantation Regional Coordination Centres manage transplant activities within the cities of its region. Each regional centre is under National Coordination Centre which is responsible for the extraction of the donated organ and tissues. It controls tissue-typing laboratories, and organ/tissue transplantation centres. The Centre also manages the medical and legal activities related to issues of finding the potential donors, identifying the potential recipients and transportation surgeries. In order to improve the coordination, it makes connections with organ transplantation centres by informing them about new donations. Moreover, regional coordinators have their organizing duty and are responsible for the transportation of procured organs to the recipient hospital and potential recipient patients to the hospital. Besides of the stated facts, each hospital/transplant centre is required to have its own coordination system, which is under the control of these regional coordination committees and regional centres.

In order to bring solutions to inefficient systems, it is important to understand and analyze an efficient one. Within this respect the national coordination system's working pattern is studied. If a hospital has permission to conduct transplantation surgeries, and if the patient has been proven to have brain death had not donated his/her organs officially before, then a brain-death committee (a group of anaesthesiologists, neurologists, neurosurgeons and cardiologists) ask for permission from donor's family for organ donation (Haberal et al. 2004). After family of the patients give permission for organ donation, the transplant coordinator of the hospital evaluates the patients in the waiting lists and identifies the most suitable patient with other members of the transplant organization. If the hospital where the donation occurs does not have a qualification as a transplantation centre, it has to notify National Coordination Centre (Haberal et al. 2004). All transplant centres and hospitals in Turkey are listed in a national ranking list for organ use. When donation happens, National Coordination Centre informs the transplant coordinator of the transplant centre/hospital whose rank is the next for getting donated organ in the nation wide ranking list. The transplant coordinator of this centre notifies this donation to the transplant organization and the team to decide on the most suitable patient for transplantation. In the case of no suitable recipient, the following transplant centre is contacted for the suitable patient for the donated organ and if there exists a suitable patient, this hospital sends transplant surgeons to the centre where organ is donated for procurement and the organ is transported to the potential recipient's hospital. Meanwhile, the coordinators contact with the potential recipient and inform them to be prepared for the urgent transplantation surgery.

Tokalak and his colleagues (Tokalak et al. 2005) mentioned that there had been a rapid increase in the number of cadaveric donation and transplantation surgeries after the foundation of the National Coordination Centre (Turkish Health 
Table 3. The Frequency of Cadaveric Organ Donation Between 2001 and 2005 in Regional Coordination Centres (Turkey).

\begin{tabular}{lccrrr}
\hline & 2001 & 2002 & 2003 & 2004 & 2005 \\
\hline Istanbul RCC & 21 & 11 & 9 & 21 & 23 \\
Izmir RCC & 28 & 39 & 50 & 67 & 68 \\
Ankara RCC & 19 & 14 & 12 & 26 & 32 \\
Antalya RCC & 18 & 27 & 24 & 9 & 8 \\
Other RCC's & 3 & 20 & 22 & 23 & 32 \\
Total donated cadeveric organ & 89 & 111 & 117 & 147 & 163 \\
\hline
\end{tabular}

Source: Turkish Republic Health Ministry (2005)

Ministry 2005) (Table 3). They suggested that organ donation and efficient allocation of organs would be further enhanced with Coordination Centre's organizing, coordinating and controlling activities and efforts (Tokalak et al. 2005). It was postulated that coordinator-based transplant organizations, such as National Coordination System in Turkey, provides better results for the collaborations of different parties within and between national/regional transplant centres and serves for the fair allocation of organs (Filipponi et al. 2005).

\section{Common Problems in Coordination and Logistics Problems in Organ Transplanta- tion}

Problems related to coordination and management of the transplantation activities and the allocation of organs

Despite the facilitating role of the organ transplant coordination systems and centres; there still exists many problems in the fair and effective management of the allocation and organ transportation (Desschans et al. 2008). The fair allocation of organs to potential organ receivers may not be achieved, since physicians have very little time to process the medical status of many potential recipient patients and decide on whom to allocate the organs. Moreover, the information flow between surgeons and the coordination centres are based on face-to face communications or direct phone contacts. The information is not stored for enhancing the communication between different coordinators, which increase the time for the get- ting contact with the target hospital, surgeons... etc.

Another source of problems occurs from the time management issues (Fuzzati 2005). The schedule of the transplant teams are linked to timetable of the physicians and other medical staff. When an organ donation occurs in a hospital where a qualified medical staff is not available, qualified physicians in other hospitals or transplant centres should travel to extract the organ. Thus, in these cases the timing of the extraction of organs depends on the schedule of the qualified physicians. If these physicians could not reach the hospital in time, the donated organ is wasted. Besides, organ donation can occur in a centre whose travel route is far from the target hospital and organ recipient. In these instances, the process of the organ allocation to another patient is restarted from the beginning, which also leads to waste of many time and increased ischemic time (Aydın et al. 2008). Furthermore, the physicians, nurses and other medical staff in the transplantation units can work part-time in organ procurement phase. This was found to waste the $70 \%$ of retrieved organs in one study (López-Navidad et al. 1999). Another major problem within the time management issue is rooted in the multi-organ donation cases. In these cases, at least two organs are donated from a brain-death case and the transplantation activities are managed for both organs.

Besides this issue, using normative and objective criteria for selecting the recipient patient, such as Model for End State liver Disease (MELD), is found to be inadequate for efficient 
allocation of organs (Koch 1996). Justice and fairness in the allocation policies are questioned in ethical terms which could be enhanced with regarding social values in choosing potential recipients. For instance, MELD de-emphasizes the waiting time of the patients and only considers the medical status of the patients. In one study, researchers found that $71 \%$ of 845 participants believe allocation policies are not fair and asserted that allocation policies should be based on more than one criterion including social values and the expectation in the public sphere (Boulware et al. 2007).

Despite the National Coordination Centre, transplant coordinators are found in only 14 transplant centres and no coordinators are found in the other 10 centres in Turkey (Tokalak et al. 2005). Since the increased number of donation and wellorganized transplant activities are achieved through transplant coordinators, the coordination of transplant activities is, thus, more poorly handled in Turkey. The higher number of professional and qualified medical specialists should be trained as transplant coordinators in Turkey (Tokalak et al. 2005).

As a good example, in one private medical organization in Turkey, its' transplantation unit developed a coordination model to handle these problems according to the Total Quality Improvement policy of their hospital (Haberal et al. 2004). At the initial step of the process, the medical staff of the transplantation unit defined the processes involved in transplantation and procurement on flowcharts. Subsequently, they identified specific managerial work, job definitions, responsibilities and duties of people involved in transplant activities and prepared an organizational chart accordingly, which then was distributed to the transplant staff. In this organization, a coordinator is responsible for the donation and procurement of organs and the qualifications of the members of the transplant team. The transplant coordinator is in continuous contact with National Coordination Centre. This organization also involves nephrologists, gastroenterologists, or pathologists as transplant clinicians who make medical examination of potential recipients. Transplant surgeons are the third leg of this organization and responsible for the preparation of suitable patients for transplantation. This model aims to enhance the communication between transplant surgeons and organize teams with people who are responsible for the ranking lists (Haberal et al. 2004). Considering the established efficient results, it is quite logical to imply that such an effective model should be patterned and a special coordinator must be provided for all transplant centres of Turkey.

Problems related to the transportation of organs/procurement medical staff

The transportation of procured organs and selected recipients are another issue involved in the logistics management of the organ transplantation. Longer transportation of procured organs often leads to a longer cold ischemic time (Aydın et al. 2008). Organs that were retrieved and transplanted in the same hospital were found to be damaged in $14 \%$ of the cases (Brockmann et al. 2006), whereas organs that were retrieved but exported to different hospitals for transplantation surgery were found to be damaged in $29 \%$ of the cases, which indicates the retrival and transplantation done in the same hospital decreases the damage rate. Delayed graft function is a common problem in renal transportation (Koning et al. 1997) and one main predictor of this problem is indicated as increased cold ischemic time. To overcome this problem, en bloc procurement of the visceral organs and mannitol administration during transplantation are used (Koning et al. 1997). Nevertheless, these precautions cannot delete the deteriorations of the procured organs and thus donor organs necessitate an urgent and immediate transportation to recipient medical centre for transplantation.

Immediate transportation of organs necessitates a well-managed transportation system. Transportation difficulties in transplant issues are, however, common in Turkey. Aydın and his colleagues (2008) examined six organ procurement processes in Ege University (School of Medicine), Organ Transplantation and Research Centre (Izmir, Turkey), between March 2005 and March 
2007. The results of the observation indiates that, since surgeons that are not the members of the hospital (where organ is donated) conduct organ procurement, the process becomes more complicated and difficult. Moreover, different surgery teams are required especially for multiorgan procurements. The surgery teams used different transportation ways to reach to the transplantation centre. Usage of highway transportation leads to increased arrival times of surgery teams leading to increased cold ischemic time of the organs. Increased ischemic times of the procreated organs affetcs the function of the organs in a negative manner. Transplantation centres sometimes get help from military services also, due to the specific transportation difficulties of Turkey. According to an information note of Turkish Military General Staff, military airplanes transported 31 organs within the last two years (Turkish General Staff 2008).

Many patients go abroad for requiring new organs and transplantation due to shortage of organs in their country. In the USA, 373 residents, whom $89.3 \%$ having kidney transplantation, were found to go abroad for transplantation surgery (Merion et al. 2008). One study conducted in Israel showed that patients with chronic liver disease who need liver transplantation flied to abroad quite safely for the long periods for transportation process, which indicates the feasibility of long-distance transportation of patients for liver transplantation (Shibolet et al. 2005). A team of hepatologists, anaesthesiologists and nurses were responsible for the logistics management - such as informing the receiving centre about the patients and medical status of the patients, managing ambulances, visas and tickets, and health insurance coverage. For the transportation of patients, a business class seat or stretcher, required medications and equipments like oxygen en route were requested from airplanes. A team of physicians who treated the patients and qualified for medical air transport of patients escorted the patient during air travel. This organization in medical travel leads to successful and efficient outcomes.

One problem with the long-distance trans- portation is discussed to be the possibility of variceal haemorrhage or increased hepatic encephalopathy, but there were no such problems within this medical travel coordination. Researchers suggested that the allocation of organs to long-distance and abroad is popular and it appers that this sort of travel for transportation is feasible for patients (Shibolet et al. 2005).

\section{Transplant tourism}

Long distance transportation of organs/ patients puts emphasis on the issue of transplant tourism. When travel for transportation involves organ trafficking (transport/harbour of organ using threat/force/fraud/deception), commercialism of the organs (organ is sold) or when travel for transportation has negative effects on the country's transportation resources, it is called as "transplant tourism" (medical value travel) (International Summit on Transplant Tourism and Organ Trafficking 2008). It was argued that transplant tourism leads to organ trafficking and organ commercialism (Khamash and Gaston 2008). Patients who have enough resources to travel to other countries, afford to "purchase" organ from other people abroad (Budiani-Saberi and Delmonico 2008). It was asserted that in some developing countries, some physicians even encourage this sort of unethical commerce. To overcome this unethical approach, Iran has made several regulations to avoid the transplant tourism within their boundaries (Ghods and Nasrollahzadeh 2005). Accordingly, people from abroad cannot take organs from Iranian residents, or Iranian patients cannot take donor organs from living (even volunteer) foreigners for kidney transplantation. Moreover, only the volunteer and the recipient that are from same nationality are allowed for organ donation and transplantation, respectively.

There is an increasing awareness on the specific transplant tourism issue in Turkey, but there is not any empirical study on this issue. According to the Declaration of Istanbul (Turkey) on Organ Trafficking and Transplant Tourism (International Summit on Transplant Tourism and Organ Trafficking 2008), transplant tourism leads 
to the exploitation of the people who sell their organs and risks the life of transplant tourists due to illegal transplantation. It is argued that one aim of the national and international transplant coordination centres should be the avoidance of the transplant trafficking and transplant tourism. It is suggested that the advertising on the organ commercialism/trafficking or tourism should be deterred and in case of existence should be severely punished.

\section{Discussion}

The efficient logistics management of the organ transplantation activities can be achieved through the decentralization of health service management and the coordination of top-down (governmental based coordination) and bottom-up agents (transplantation-based coordination). To achieve this organization, governmental support is required (Shaewkey and Hart 2003). The essential role of logistics management in successful organ transplantation activities, as in the case of transportation, should be well understood by the policy makers. This paper also contributes to this sort of understanding which leads to improvement in organization thus eliminating some and decreasing other negative ineffective results and unethical approaches. Moreover, the procurement planning of the organ transplantation activities should be developed by roughly specifying the organ donation rates before brain death and the contact information of the people who donate their organs in their lifetime. The organizations involved in inter/national coordination systems could utilize the experiences of private health care centres (such as organizing transplantation activities by total quality management model) in managing the organ transplantation activities. The coordination of the hospital-based organ transplantation coordinators and governmental-based coordinators should be enhanced by improving communications among these agents (Shaewkey and Hart 2003).

Several methods, organizing techniques and managerial policies may be applied to handle and overcome the transportation difficulties happening during organ transplantation. First, special trans- portation facilities (air travel or land travel) may be organized for transport travel activities, such as organ procurement, potential recipient transportation. In order to enhance the travel duration especially in land travel, special ambulances or vehicles could be assigned to transplant teams and potential recipients whose medical condition requires special medical equipments like oxygen while travelling. These ambulances/vehicles could be specified with different distinguished colour, which can be easily recognized after effective public information training Drivers could also be informed about the upcoming of these special land vehicles via emergency traffic news. Alternative routes of these vehicles should be predetermined before the travel. As an example, one airline company provides service for such emergency situation logistics (Ghods and Nasrollahzadeh 2005). The delivery to European countries is achieved within three hours of the same day procurement. This service provides priority to the emergent consignments, such as medical equipments, or medicines. It collaborates with clients for special preservation of consignments and possible interventions in critical situations during delivery. This kind of service could also be used for the transportation of organs or travel of candidate recipients to other countries for transplantation. This system could also be incorporated to the organ transplantation systems in Turkey. The applicability of this system in Turkey and the feasibility should be further studied.

Besides, the ethical considerations should be taken into consideration in transport travel abroad by governmental regulations, as well as private travel agencies, who can collaborate with national or international transplant coordination centres or governments to solve the organ tourism problem. The Istanbul Declaration on Organ Trafficking and Transplant Tourism is one step ahead for these ethical considerations, but similar acceptance and understanding should also be shared by organ transplant managers and coordination teams.

Difficulties in organ transplantation activities specific to the case of Turkey can be related 
to low level of the public awareness on organ transplantation even in the medical society. With the increased number of the transplantation units in private hospitals, the revenue related issues in organ transplantation are considered. The policy makers and the hospital managers become aware of the need of more coordinated organ transplantation activities, quite recently. Besides this fact, there are scarce empirical findings on the efficiency of logistic activities of organ transplantation. Most of the empirical studies focused on the transportation of organs, but the transport of potential recipients to other cities within a given country for transportation has not been emphasized. Specifically, the organization of both organ allocation strategies and the transportation of the potential recipients should be coherently analyzed and researched in depth in the future studies. Moreover, the transplant tourism within Turkey has not been studied in detail. It is recommended that the future studies on this topic need to focus on the transplant tourism issue in Turkey, focusing on the adverse effects of this phenomenon on Turkish health structures and common public opinion about organ donations. The social values of Turkish people regarding how organs are allocated could, also, be analyzed in further studies. Depending on the Turkish society's attitudes and expectations on the fairness of the organ allocation, culture specific allocation modifications may be organized.

\section{Conclusion}

Organ transplantation requires an integrated logistic management system for the coordination of different agents (i.e. coordinators, physicians, patients, donors) and different centres (i.e. organ transplant centres, hospitals, national/regional/ local coordination centres). This paper reviews the existing problems like lack of coordination, lack of centrally controlled organization, unethical approaches in logistics management of the organ transplantation. It puts emphasis on a systematic regard of the organ transplantation from logistics point of view and it provides solutions to managerial problems in terms of allocation and transportation of organs. A systematic coordina- tion of the medical and logistics perspective are important for effective organ transplantation procedures and for saving many lives of people that require organ transplantation surgery for recovery.

\section{References}

Aydın, U., Yazıcı, P., Kazımı, C., Bozoklar, A., Sozbilen, M., Zeytunlu, M. \& Kilic, M. (2008) Simultaneous air transportation of the harvested heart and visceral organs for transplantation. Transplant. Pro., 40, 44-46.

Boulware, L.E., Troll, M.U., Wang, N.Y. \& Powe, N.R. (2007) Perceived transparency and fairness of the organ allocation system and willingness to donate organs: a national study. Am. J. Transplant., 7, 1778-1787.

Brockmann, J.G., Vaidya, A., Reddy, S. \& Friend, P.J. (2006) Retrieval of abdominal organs for transplantation. $B r . J$. Surg., 93, 133-142.

Budiani-Saberi, D.A. \& Delmonico, F.L. (2008) Organ trafficking and transplant tourism: a commentary on the global realities. Am. J. Transplant., 8, 925-929.

Coombes, J.M. \& Trotter, J.F. (2005) Development of the Allocation System for Deceased Donor Liver Transplantation. Clinic. Med. \& Res., 3, 87-92.

Desschans, B., Van Gelder, F., Van Hees, D., de Rocy, J., Monbaliu, D., Aerts, R., Coosemans, W. \& Pirenne, J. (2008) Evolution in allocation rules for renal, hepatic, pancreatic and intestinal grafts. Acta. Chir. Belg., 108, 31-34.

Edirne, T. (2004) Türkiye'de organ ve doku nakli uygulamaları: sonuçları ve strateji önerileri. Türk. Klinik., 266, 24-32.

Filipponi, F., De Simone, P. \& Mosco, F. (2005) Appraisal of the coordinator-based transplant organizational model. Transplant. Proc., 37, 2421-2422.

Fuzzati, R. (2005) Organ Transplantation Management. Swiss Federal Institute of Technology Lausanne (EPFL) Technical Report, No: IC/2005/022.

Ghods, A.J. \& Nasrollahzadeh, D. (2005) Transplant tourism and the Iranian model of renal transplantation program: ethical considerations. Exp. Clin. Transplant., 3, 351-354.

Haberal, M., Moray, G., Boyacioglu, S., Turgut, N., Haberal, C., Turan, M., Arslan, G. \& Erdal, R. (2004) Transplant coordination activities in the Baskent University Hospital Network. Prog. Transplant., 14, 10-14.

International Summit on Transplant Tourism and Organ Trafficking. (2008) The declaration of Istanbul on organ trafficking and transplant tourism. Clin. J. Am. Soc. Nephrol., 3, 1227-1231.

Khamash, H.A. \& Gaston, R.S. (2008) Transplant tourism: a modern iteration of an ancient problem. Curr. Opin. Organ Transplant., 13, 395-399.

Koch, T. (1996) Normative and prescriptive criteria: the efficacy of organ transplantation allocation protocols. Theor. Med., 17, 75-93.

Koning, O.H.J., Ploeg, R.J., van Bockel, J.H., Groenewegen, M., van der Woude, F.J., Persijn, G.G. \& Hermans, J. (1997) Risk factors for delayed graft function in cadaveric kidney transplantation: a prospective study of renal function and graft survival after preservation with university of Wisconsin solution in multi-organ donors. Transplant., 63, $1620-1628$.

López-Navidad, A., Caballero, F., Domingo, P., Esperalba, J. \& Viedma, M.A. (1999) Hospital professionalization of the organ procurement process maximizes the retrieval poten- 
tial. Transplant. Pro., 31, 1039.

Matesanz, R., Miranda, B. \& Felipe, C. (1994a) Organ procurement and renal transplants in Spain: the impact of transplant coordination. Nephrol. Dial. Transpla., 9, 475-478.

Matesanz, R., Miranda, B. \& Felipe, C. (1994b) Organ procurement in Spain: impact of transplant coordination. Clinic. Transplant., 8, 281-286.

Merion, R.M., Barnes, A.D., Lin, M., Ashby, V.B., McBride, V., Ortiz-Rios, E., Welch, J.C., Levine, G.N., Port, F.K. \& Burdick, J. (2008) Transplants in foreign countries among patients removed from the US transplant waiting list. Am.J. Transplant., 8, 988-996.

Miranda, B., Naya, M.T., Cuende, N. \& Matesanz, R.M. (1999) The Spanish model of organ donation for transplantation: Donor management and procurement. Curr. Op. Organ Trans., 4, 109.

Polak, W.G., Chudoba, P., Patrzalek, D. \& Szyber, P. (2000) How local transplant coordinators might increase the number of potential donors: our experience in lower Silesia. Transplant. Pro., 32, 68.

Reynolds, R.L. \& Barney, L.D. (1988) Economics of organ procurement and allocation. J. Econ. Issues, 2, 571-579.

Shaewkey, P. \& Hart, C. (2003) Logistics' contributions to better health in developing countries. Ashgate: Burlington.

Shibolet, O., Rowe, M., Safadi, R., Levy, I., Zamir, G., Eid, A., Donchin, Y., Ilan, Y. \& Shouval, D. (2005) Air transportation of patients with end-stage liver disease to distant liver transplantation centers. Liver Transplant., 11, 650-655.

Tokalak, I., Karayali, H., Moray, G., Bilgin, N. \& Haberal, M.
(2005) Coordinating organ transplantation in Turkey: effects of the National Coordination Center. Prog. Transplant., 15, 283-285.

Turkish General Staff (2008) Information Note. Retrieved October 28, 2008, from http://www.tsk.mil.tr/10_ARSIV/ 10_1_Basin_Yayin_Faaliyetleri/10_3_Bilgi_Notlari/2008/ BN_43.html

Turkish Republic Health Ministry (2002) National organ and tissue transplantation coordination system report Retrieved October 28, 2008, from http://www.bsm.gov.tr/mevzuat/ docs/Y_01062000_1.pdf.

Turkish Republic Health Ministry (2005) Organ transplantation statistical data. Retrieved November 9, 2008, from http:// www.istanbulsaglik.gov.tr/w/sb/tedk/pdf/organ_nakli_ genel_istatistikler.pdf.

Van Gelder, E., de Roey, J., Desschans, B., Van Hees, D., Aerts, R., Monbaliu, D., De Pauw, L., Coosemans, W. \& Pirenne, J. (2008) What is the limiting factor for organ procurement in Belgium: donation or detection? What can be done to improve organ procurement rates? Acta. Chir. Belg., 108, 27-30.

Van Hees, D. \& Van Gelder, F. (2008) Importance of informatics and database management in transplant coordination. Acta. Chir. Belg., 108, 22-26.

Wiesner, R. (2003) Model for end-stage liver disease (MELD) and allocation of donor livers. Gastroentro., 124, 91-96.

Williams, M.G., Ferree, D., Bollinger, R. \& Lefore, W. (1984) Reasons why kidneys removed for transplantation are not transplanted in US. Transplant., 38, 691-694. 